\title{
CLASSIFICATION OF PSEUDOMONAS AERUGINOSA O ANTIGENS BY IMMUNOELECTROPHORESIS
}

\author{
B. LÁNyi, Maria M. ÁdÁm ANd ANNA SZENTMiHÁlyI \\ National Institute of Public Health, H-1966 Budapest, POB 64, Hungary
}

IN a study reported previously (Lányi and Ádám, 1973), it was shown that double agar-gel precipitation and agglutination give, as a rule, identical crossreaction patterns for the $\mathrm{O}$ antigens of Pseudomonas aeruginosa. On the basis of precipitation of different kinds of bacterial extract, the antigens were classified into the following groups: (1) those of which saline extracts, supernates of phenol-water extracts $\left(\mathrm{L}_{1}\right.$ fractions) and purified lipopolysaccharide (LPS) precipitated readily with homologous antisera; (2) those in which saline extracts and LPS precipitated but $L_{1}$ fractions did not; and (3) two partial antigens, none of the extracts of which precipitated with absorbed antisera, although the presence of the antigen was demonstrable by means of agglutination tests. In the experiments described in this paper, a further classification of $P$. aeruginosa $\mathrm{O}$ antigens was attempted.

\section{MATERIALS AND METHODS}

Bacterial strains. Twenty-three $P$. aeruginosa cultures represented Lányi's $O$-antigen type strains (Lányi, 1966-67 and 1970); in addition, 53 strains of different serogroups were chosen from our collection. Of 13 strains received from Professor P. V. Liu, Louisville, Kentucky, USA, as type strains of the provisional international $P$. aeruginosa antigenic scheme, 12 originated from Habs (1957) and one from Sandvik (1960). Saline extracts were made from all these cultures, but only Lányi's 23 O-antigen type strains were used for the preparation of $L_{1}$, LPS, trichloracetic-acid (TCA) and alkali extracts.

Antigens. Extracts in physiological saline ("saline") were prepared by heating the bacterial suspension at $100^{\circ} \mathrm{C}$ for $2 \frac{1}{2} \mathrm{~h}$; each $\mathrm{ml}$ of the supernate obtained after centrifugation represented c. $30 \mathrm{mg}$ of bacteria (moist weight). $\mathrm{L}_{1}$ fractions were the freeze-dried supernates of ultracentrifuged phenol-water extracts; nucleic acid-free LPS preparations were dialysed and freeze-dried phenol-water extracts purified by ultracentrifugation at $105,000 \mathrm{~g} . \mathrm{L}_{1}$ and LPS solutions were prepared for precipitation by dissolving $5 \mathrm{mg}$ of the freeze-dried preparation in saline and heating at $100^{\circ} \mathrm{C}$ for $1 \mathrm{~h}$. The preparation of these antigens was described in detail by Ádám, Kontrohr and Horváth (1971) and by Lányi and Ádám (1973).

The bacteria were, as a rule, grown in Roux flasks at $37^{\circ} \mathrm{C}$ for $24 \mathrm{~h}$ on nutrient-agar medium: beef extract (Central Slaughterhouse, Budapest) $15 \mathrm{~g}$; peptone (Richter, Budapest) $10 \mathrm{~g}$; $\mathrm{NaCl} 3 \mathrm{~g} ; \mathrm{Na}_{2} \mathrm{HPO}_{4} .12 \mathrm{H}_{2} \mathrm{O} 4 \mathrm{~g}$; agar $18 \mathrm{~g}$; tap water $1000 \mathrm{ml} ; p \mathrm{H} \mathrm{7.4}$. Bloodagar cultures were grown on plates containing baker's yeast $40 \mathrm{~g}$; peptone (Richter, Budapest) $10 \mathrm{~g} ; \mathrm{NaCl} 3 \mathrm{~g} ; \mathrm{Na}_{2} \mathrm{HPO}_{4} .12 \mathrm{H}_{2} \mathrm{O} 4 \mathrm{~g}$; agar $18 \mathrm{~g}$; tap water $1000 \mathrm{ml} ; p \mathrm{H} \mathrm{7.4;} \mathrm{ox} \mathrm{blood}$ $50 \mathrm{ml}$.

TCA extracts were prepared by suspending $5 \mathrm{~g}$ of dry bacteria or $10 \mathrm{~g}$ of moist bacteria in $50 \mathrm{ml}$ of ice-cold TCA $10 \%(\mathrm{w} / \mathrm{v})$. The suspension was left to stand in the refrigerator at $4^{\circ}-6^{\circ} \mathrm{C}$ for $24-48 \mathrm{~h}$ and then centrifuged. After a second extraction of the deposit, the 
supernates were pooled and dialysed. The concentrated and freeze-dried extract was dissolved in saline $(2 \mathrm{mg}$ per $\mathrm{ml}$ ) and used without heating.

Alkali extracts were made by suspending washed bacteria in $0.5 \mathrm{M}$ sodium hydroxide and heating at $80^{\circ} \mathrm{C}$. At intervals, samples were removed from the water bath, neutralised with hydrochloric acid and used as antigens for immunoelectrophoresis. The salts were removed by dialysis from several of the alkali-treated extracts. Each $\mathrm{ml}$ of alkali extract represented c. $30 \mathrm{mg}$ of bacteria (moist weight).

Antisera were prepared in rabbits with bacteria heated at $75^{\circ} \mathrm{C}$ for $1 \mathrm{~h}$ (Lányi, 1966-67).

Immunoelectrophoresis. Each slide $(25 \times 75 \mathrm{~mm})$ was covered with $3.5 \mathrm{ml}$ of gel containing $\mathrm{K}_{2} \mathrm{HPO}_{4}, 2.61 \mathrm{~g}$; $\mathrm{KH}_{2} \mathrm{PO}_{4}, 2.04 \mathrm{~g}$; Oxoid Agar No. $1,9 \mathrm{~g}$; merthiolate, $0.1 \mathrm{~g}$; water, $1000 \mathrm{ml}$. The extracts were electrophoresed in $10-\mu l$ amounts from wells $3 \mathrm{~mm}$ in diameter with merthiolate-treated potassium-phosphate buffer $(0.03 \mathrm{M}, p \mathrm{H} 6.9)$ at a gradient of $6 \mathrm{~V}$ per $\mathrm{cm}$ and at $3.7 \mathrm{~mA}$ per slide for $120 \mathrm{~min}$. At the end of electrophoresis, a median
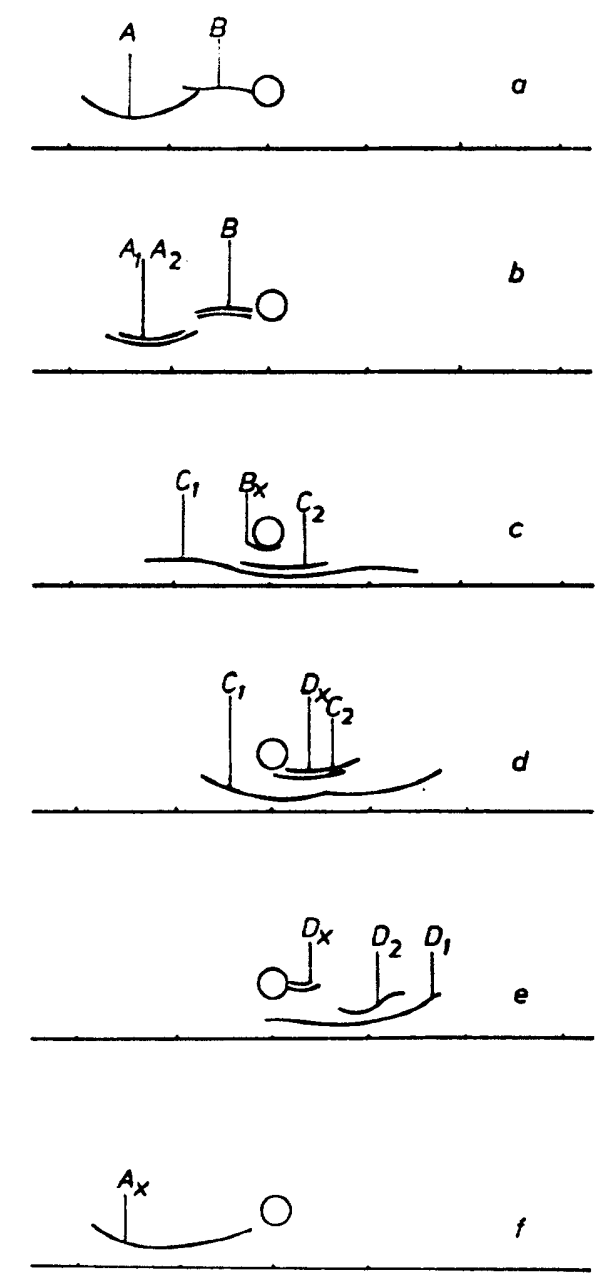

FIG. 1.-Precipitation arcs obtained with saline extracts of Pseudomonas aeruginosa antigens. $a=$ immunoelectrophoretic (IE)-groups Ia and Ib; $b=$ IE-group Ic; $c=$ IE-group II; $d=$ IE-group III; $e=$ IE-group IV; $f=$ IE-group V. Anode on left; each division on the scale $=10 \mathrm{~mm}$. 
trench, $1.5 \mathrm{~mm}$ in width was cut parallel to the line of current flow and filled with $50 \mu \mathrm{l}$ of antiserum. Then the slides were incubated in a moist chamber at $37^{\circ} \mathrm{C}$ and examined after incubation for $24 \mathrm{~h}$. Staining was performed with amido-black (Uriel, 1971).

Recording of the position and intensity of the precipitation arcs. Stained and dried slides were recorded in the Zeiss ERI $65 \mathrm{~m}$ automatic densitometer supplied with a 560-nm filter. Photometric densities of the arcs were plotted against the distance along the long axis of the slide on both the anode (left-hand) and the cathode (right-hand) side of the well.

Designation of precipitation lines. The arcs were arbitrarily termed, according to localisation, $\mathrm{A}^{+}(+30$ to $+15 \mathrm{~mm}), \mathrm{A}(+20$ to $+8 \mathrm{~mm}), \mathrm{B}(+10$ to $0 \mathrm{~mm}), \mathrm{C}(+10$ to $-5 \mathrm{~mm})$, $\mathrm{D}(0$ to $-20 \mathrm{~mm})$. Double or triple lines were termed $A_{1}, A_{2}$ etc. Precipitates probably not identical with lines $A, B, C$ or $D$, but showing the same migration rate, were designated respectively $A_{\mathbf{x}}, B_{\mathbf{x}}, C_{\mathbf{x}}$ and $D_{\mathbf{x}}$.

\section{RESULTS}

\section{Immunoelectrophoretic patterns of saline extracts}

Saline extracts of a total of 89 strains representing all recognised $P$. aeruginosa antigens were electrophoresed against the homologous antisera. The cultures fell into distinct immunoelectrophoretic (IE) groups, some of which, on the basis of the behaviour of other kinds of extract, were classified into IE subgroups. As seen in fig. 1, members of IE-groups Ia and Ib were characterised by a thick arc toward the positive electrode (A) and a somewhat thinner line (B) that started from the edge of the antigen well and usually fused at its anodic end with arc A. Subgroup Ic showed lines somewhat different from this pattern. Cultures classified into IE-group II gave a line $\left(C_{1}\right)$ ranging from $10-15 \mathrm{~mm}$ on the positive to $10-15 \mathrm{~mm}$ on the negative side of the antigen well, one shorter line $\left(C_{2}\right)$ more towards the cathode side, and a short line $\left(B_{\mathbf{x}}\right)$ extending from the starting well towards the anode. IE-group III gave lines $C_{1}$ and $C_{2}$, and a short line $\left(D_{x}\right)$ towards the negative electrode. IE-group IV

TABLE

Immunoelectrophoretic (IE) characteristics of Pseudomonas aeruginosa antigens

\begin{tabular}{|c|c|c|c|c|c|c|c|}
\hline \multirow{3}{*}{ IE group } & \multicolumn{6}{|c|}{ Procipitation arcs, in tests with homologous antiserum, given by } & \multirow{3}{*}{$O$ antigens* } \\
\hline & \multirow{2}{*}{$\begin{array}{c}\text { saline } \\
\text { extract }\end{array}$} & \multirow{2}{*}{$\underset{\text { fraction }}{L_{1}}$} & \multirow{2}{*}{$\underset{\text { fraction }}{\text { LPS }}$} & \multirow{2}{*}{$\underset{\text { extract }}{\text { TCA }}$} & \multicolumn{2}{|c|}{ alkali extract } & \\
\hline & & & & & $(\mathrm{NaOH} 1 \mathrm{~h})$ & $(\mathrm{NaOH} 24 \mathrm{~h})$ & \\
\hline Ia & A, $\mathbf{B}$ & $\mathbf{A}, \mathbf{B}$ & $A, B, C_{x}$ & $A, B, C_{\mathbf{x}}$ & $\mathbf{A}^{+}$ & - & 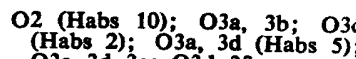 \\
\hline $\begin{array}{l}\text { Ib } \\
\text { Ic }\end{array}$ & $\underset{\mathbf{A}, \mathbf{B}}{\mathbf{A}, \mathbf{B}}$ & $\underset{\mathbf{A}, \mathbf{B}}{\mathbf{A}}$ & $\stackrel{A}{A}, \mathbf{B}, \mathrm{C}_{\mathbf{x}}$ & $\begin{array}{l}\mathbf{A}, \mathbf{B}, \mathbf{C}_{\mathbf{x}} \\
\mathbf{A}, \mathbf{B}, \mathbf{C}_{\mathbf{x}}\end{array}$ & $\underline{\mathbf{A}}$ & 二 & 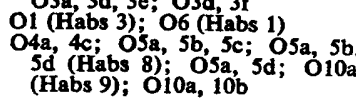 \\
\hline II & $B_{2}, C_{1}, C_{2}$ & $\mathrm{C}_{1}, \mathrm{C}_{2}$ & $C_{1}, C_{2}, C_{x}$ & $C_{1}, C_{2}, C_{x}$ & 一 & - & $04 a, 4 b ; 04 a, 4 d$ \\
\hline$\underset{\text { IIIIa }}{\text { III }}$ & $\begin{array}{l}C_{1}, C_{2}, D_{x} \\
C_{1}, C_{2}, D_{x}\end{array}$ & $\mathrm{C}_{1}, \mathrm{C}_{2}$ & $\underset{C_{x}}{C_{1}, C_{2}, C_{x}}$ & $\begin{array}{l}\mathbf{C}_{1}, \mathbf{C}_{2}, \mathbf{C}_{\mathbf{x}} \\
\mathbf{C}_{1}, \mathbf{C}_{2}, \mathbf{C}_{\mathbf{x}}\end{array}$ & $\underset{\mathbf{A}}{\mathbf{C}}$ & $\underset{\mathbf{A}}{\mathbf{C}}$ & $\begin{array}{l}\text { O12 } \\
\text { O13 (Habs 12) }\end{array}$ \\
\hline IV & $D_{1}, D_{2}, D_{x}$ & - & $\mathbf{C}_{\mathbf{x}}$ & $D_{1}, D_{2}, C_{\mathbf{x}}$ & $\mathbf{D}$ & $\mathbf{D}$ & $\begin{array}{l}\text { O7a, 7b (Habs 11);07a, 7c; } 011 \\
\text { (Habs 4) }\end{array}$ \\
\hline $\mathbf{v}$ & $\mathbf{A}_{\mathbf{x}}$ & - & $A_{x}, C_{x}$ & - & - & - & $08 ; 09$ \\
\hline
\end{tabular}

* O antigens are designated according to Lányi's antigenic scheme (1966-67); bracketed figures indicate the corresponding groups of Habs (1957).

$-=$ No arc seen. 


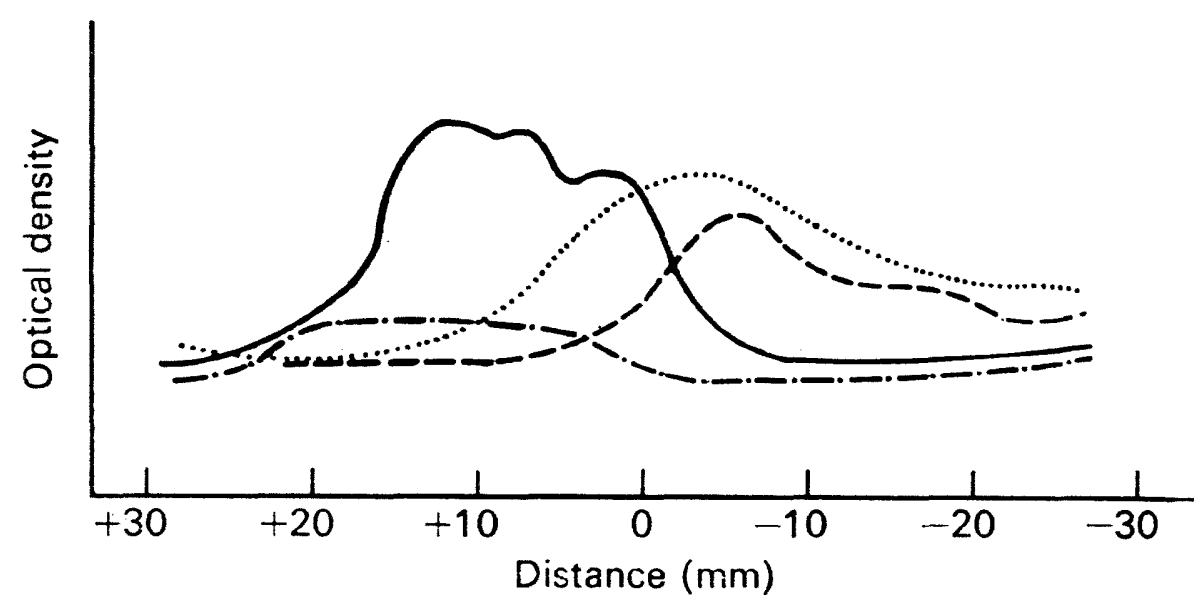

FIG. 2.-Densitometric curves representing the main immunoelectrophoretic types obtained with saline extracts of $P$. aeruginosa: $-=$ IE-group Ia (strain O3a, 3d); $\cdots \cdots \cdots . . . . .=$ IE-group IIIa (strain 012); - - - = IE-group IV (strain 07a, 7b); - - - = IE-group V (strain O8).

strains formed, in addition to line $D_{x}$, two arcs on the cathode side $\left(D_{1}\right.$ and $\left.D_{2}\right)$. Two strains, no. 170017 (O-group 8) and no. 170018 (O-group 9), which were placed in a separate IE-group $V$, differed from all other cultures in exhibiting only a thin line at the site of line $A\left(A_{\mathbf{x}}\right)$. A visible line $A_{\mathbf{x}}$ was produced only if the extract had been prepared from 3-day-old blood-agar cultures containing about three times the usual amount of bacteria (see Materials and methods). Precipitation arcs obtained with saline extracts are listed in the 2nd column of the table.

For a more accurate comparison of density and sites of the precipitation arcs, stained immunoelectrophoretic slides were recorded by microdensitometry. Fig. 2 shows that lines distinguishing the IE groups can be well demonstrated by photoelectric measurement. Arc A contained the greatest amount of precipitate; the other line characteristic of IE-group I was next in order. Line A ranged from +20 to $+8 \mathrm{~mm}$ and had a peak at $+15 \mathrm{~mm}$, while line B ranged from +10 to $0 \mathrm{~mm}$ with a peak at $+8 \mathrm{~mm}$, where it fused with line A. IE-group II (not shown in fig. 2) had a density curve between +10 and $-10 \mathrm{~mm}$, with a peak at $0 \mathrm{~mm}$. IE-group-III antigens were characterised by curves shifted more to the negative side $(+3$ to $-15 \mathrm{~mm})$, with a peak at $-5 \mathrm{~mm}$. IE-group-IV extracts precipitated definitely towards the cathode, ranging from about 0 to $-20 \mathrm{~mm}$, but formed a peak practically at the same site as group-III antigens. The usually multiple arcs for strains of IE-groups II, III and IV consisted frequently of faint lines; the relatively high peaks are explained by the fact that photoelectric measurement reflected the total density of precipitates falling at the same site along the long axis of the slide. The low peak of line $A_{x}$ is in agreement with the faint precipitation shown by IE-group-V strains. Density curves were localised similarly for all strains belonging to the same IE group, only the amplitude of the curve varied with the amount of precipitate formed, that is, with the titre of the serum. 

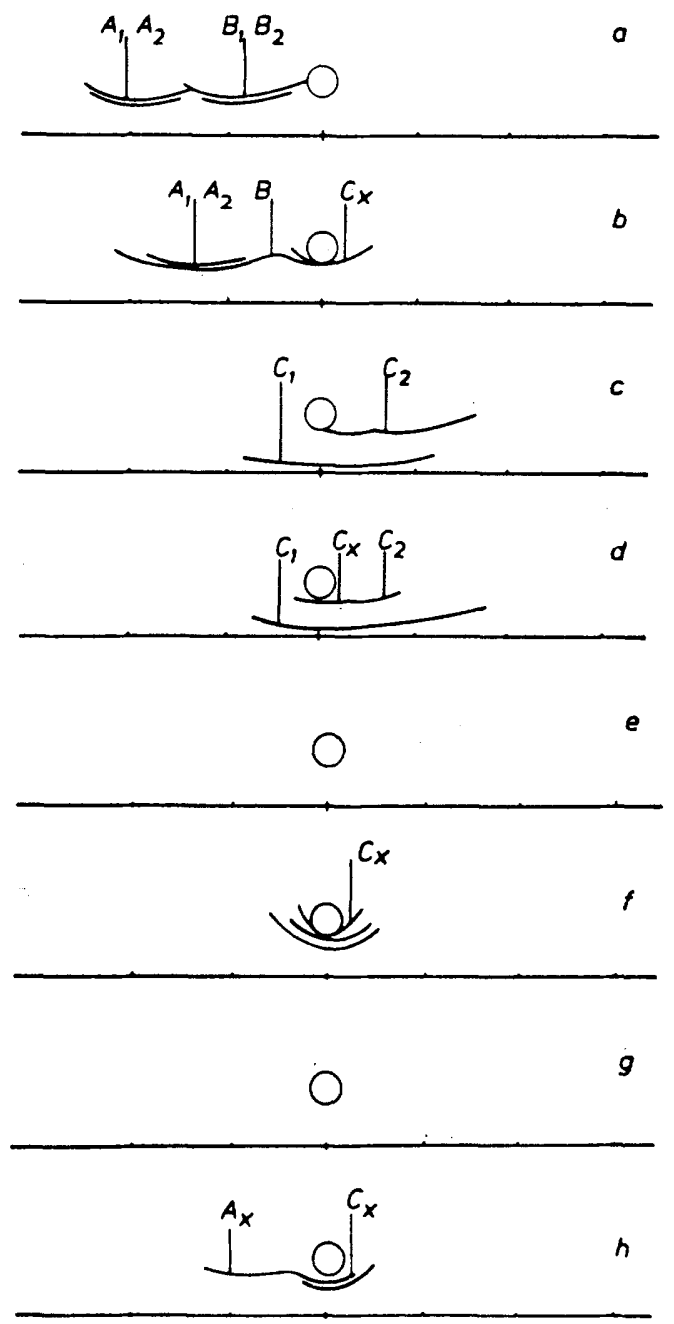

FIG. 3.-Precipitation arcs obtained with $P$. aeruginos $a \mathrm{~L}_{1}$ and LPS fractions: IE-group $\mathrm{I}, a=\mathrm{L}_{1}$ and $b=$ LPS; IE-groups II and IIIa, $c=\mathrm{L}_{1}$ and $d=$ LPS; IE-groups IIIb and IV, $e=\mathrm{L}_{1}$ and $f=\mathrm{LPS}$; IE-group $\mathrm{V}, g=\mathrm{L}_{1}$ and $h=\mathrm{LPS}$. See also legend to fig. 1 .

\section{Immunoelectrophoretic patterns of $L_{1}$ and LPS extracts}

The immunoelectrophoretic patterns given by $\mathrm{L}_{1}$ and LPS preparations of the 23 type strains of Lanyi's antigenic scheme are shown in fig. 3. With the majority of strains, the $L_{1}$ extracts gave patterns very similar to those of the saline extracts; but with IE-group-I strains, the $\mathrm{L}_{1}$ extracts-unlike saline extracts-usually formed a double $B$ line $\left(B_{1}, B_{2}\right)$ and arc $A$ also frequently consisted of two parallel lines $\left(A_{1}, A_{2}\right)$. The $L_{1}$ fractions of strains of IEgroups IIIb, IV and V failed to precipitate (3rd column of the table).

LPS fractions of IE group-I, -II and -IIIa strains gave similar results to those obtained with the corresponding saline extracts, except that a short arc at 


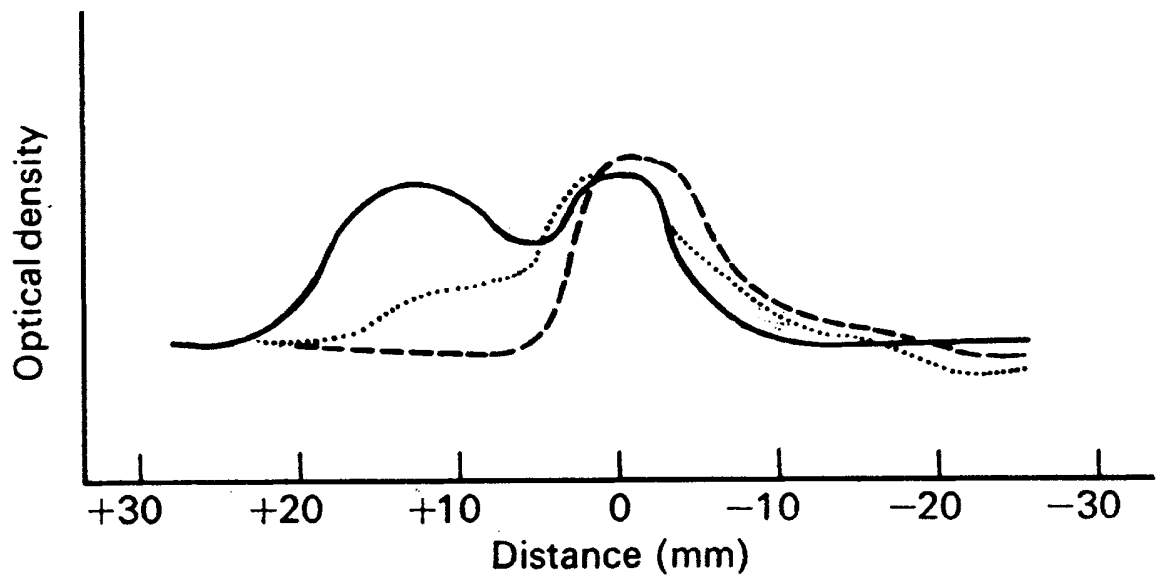

FIG. 4.-Densitometric curves representing the main immunoelectrophoretic types obtained with LPS fractions of $P$. aeruginosa; $-=$ IE-group Ia (strain O3a, 3d); $\cdots \cdots \cdots \cdots=$ IE-group II (strain O4a, 4d); ----- = IE-group IV (strain 07a, 7b).
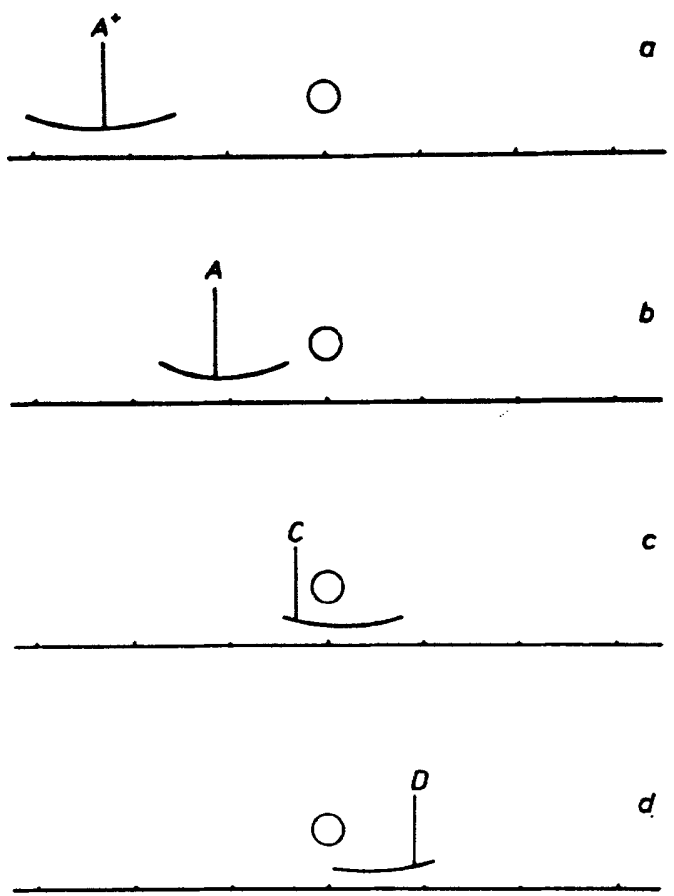

FIG. 5.-Precipitation arcs obtained with $P$. aeruginosa antigens after exposure to $0.5 \mathrm{~N}$ sodium hydroxide for $1 \mathrm{~h}$ at $80^{\circ} \mathrm{C}: a=$ IE-group Ia; $b=$ IE-group Ib; $c=$ IE-group IIIa; $d=$ IEgroup IV. See also legend to fig. 1. 


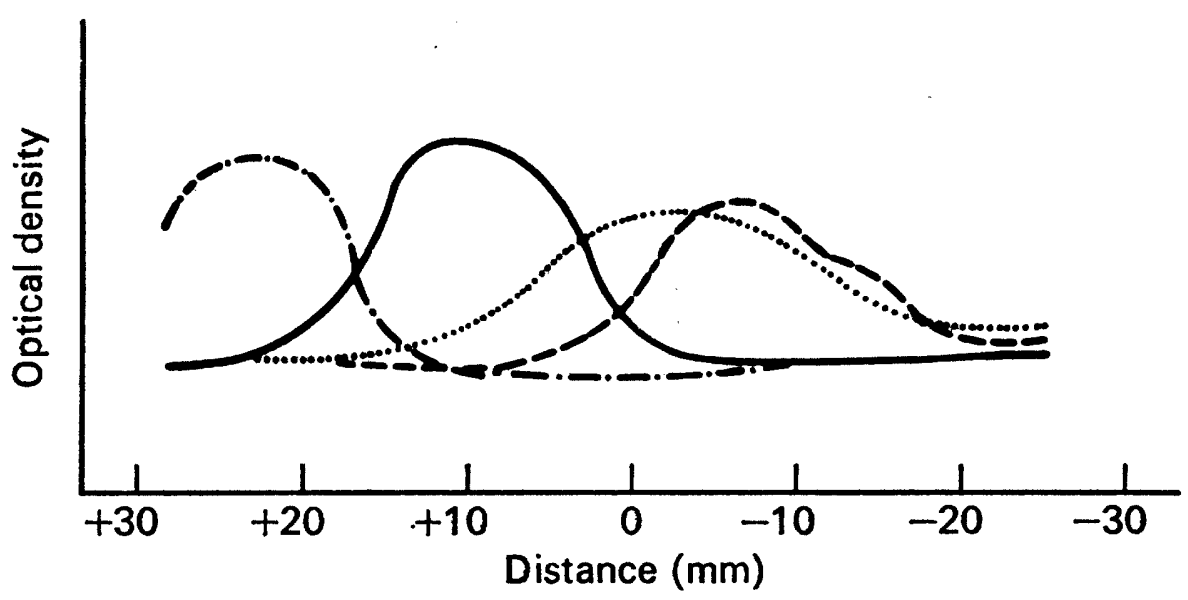

FIG. 6.-Densitometric curves for precipitation arcs obtained with $\boldsymbol{P}$. aeruginosa antigens after exposure to $0.5 \mathrm{M}$ sodium hydroxide for $1 \mathrm{~h}$ at $80^{\circ} \mathrm{C}$ : $\underline{-}=$ IE-group Ib (strain O6); …...... = IE-group IIIa (strain O12); (strain $07 \mathrm{a}, 7 \mathrm{~b}$ ).

the site of the starting well $\left(\mathrm{C}_{\mathbf{x}}\right)$ was always present; traces of this arc were sometimes observed with $L_{1}$ fractions. LPS fractions of strains of groups IIIb and IV differed from the rest in the absence of lines corresponding to those produced with saline extracts; arc $\mathrm{C}_{\mathbf{x}}$, however, was formed by these antigens (4th column of the table).

Fig. 4 shows densitometric recordings for some LPS fractions. The similarity of the LPS curves to the saline-extract curves (fig. 2) is evident for IEgroups I and II. The definite peak at $0 \mathrm{~mm}$ in the LPS curves is due to the presence of line $\mathrm{C}_{\mathrm{x}}$. IE-group IV, the LPS fraction of which formed only arc $\mathrm{C}_{\mathrm{X}}$, exhibited a sharply rising and falling curve at the site of the antigen well.

\section{Immunoelectrophoretic patterns of trichloracetic acid extracts}

As shown in the 5th column of the table, the TCA extracts usually gave precipitation arcs similar to those of the corresponding LPS fractions, that is, they showed the presence of a short arc at the starting well $\left(C_{\mathrm{x}}\right)$ in addition to lines seen with saline extracts. TCA extracts of strains of IE-group IV differed from LPS fractions in the presence of lines $D_{1}$ and $D_{2}$. TCA extracts of group-V strains failed to react.

\section{Immunoelectrophoretic patterns of alkali extracts}

Heating at $80^{\circ} \mathrm{C}$ with $0.5 \mathrm{M}$ sodium hydroxide allowed a further subdivision of $P$. aeruginosa antigens; fig. 5 shows the main types of precipitation arcs and fig. 6 demonstrates the main types of density curves observed. After treatment for $1 \mathrm{~h}$ with alkali, antigens of IE-group Ia precipitated more toward the anode than did those in the corresponding saline extracts and thus formed a new arc termed $\mathrm{A}^{+}$; alkali-treated antigens of IE-group $\mathrm{Ib}$ showed the 
usual migration rate (5th column of the table). These extracts were moderately resistant to alkali in that they still reacted after exposure for $5 \mathrm{~h}$ but not after $24 \mathrm{~h}$. Antigens belonging to IE-groups III and IV were highly resistant to alkali. It is remarkable that the corresponding saline extracts in groups III and IV gave multiple precipitation lines, whereas the alkali-treated antigens usually formed single arcs. The rest of the antigens, belonging to IE-groups Ic, II and IV, were sensitive to alkali, losing their precipitating ability after exposure to sodium hydroxide for $15-60 \mathrm{~min}$.

Classification of $P$. aeruginosa antigens, determined on the basis of agglutination, into immunoelectrophoretic groups is summarised in the table.

\section{Cross-reactions between related antigenic groups}

Extracts of type strains shown by agglutination (Lányi, 1966-67) and by double agar-gel precipitation (Lányi and Ádám, 1973) to share major partial antigens gave the corresponding cross-reactions in immunoelectrophoresis. The lines developing with the heterologous antiserum were usually less marked than those with the homologous serum, but appeared always at the same site and in a closely similar form.

\section{Discussion}

The results of the present experiments showed a close correspondence between the electrophoretic mobility and the serological classification of $P$. aeruginosa antigens; strains falling into the same antigenic group or sharing major partial antigens exhibited the same immunoelectrophoretic pattern. Strains with the $\mathrm{O}$ antigen $4 \mathrm{a}, 4 \mathrm{c}$ differed in this respect from other $\mathrm{O} 4$ cultures, but in the rest of the properties examined (alkali sensitivity, behaviour of $L_{1}$ and LPS fractions) all $\mathrm{O} 4$ strains were uniform.

The failure of $\mathrm{L}_{1}$ fractions of antigens $\mathrm{O} 7 \mathrm{a}, \mathrm{7b}, \mathrm{O} 7 \mathrm{a}, 7 \mathrm{c}, \mathrm{O}, \mathrm{O}, \mathrm{O}, \mathrm{O} 11$ and $\mathrm{O} 13$ to precipitate was first observed by Ádám and Kontrohr (1970, unpublished data) and was described by Lányi and Ádám (1973). Because lines A and B, $C_{1}$ and $C_{2}$, as well as $D_{1}$ and $D_{2}$, represent probably the side chain of the antigen molecule, it may be assumed that the above antigens contained no side chains appearing in the $L_{1}$ fraction.

The unusual behaviour of antigens 08 and 09 deserves some interest. These two cultures differed from the others in that they produced weakly reacting saline and LPS extracts, their TCA fractions failed to precipitate and their suspensions were only moderately immunogenic in rabbits. These findings confirm earlier assumptions (Ádám et al., 1971; Lányi and Ádám, 1973) that the main antigens in these strains are R-like factors. It is noticeable that line $C_{x}$, a short, usually semicircular arc at the starting well, was present in the LPS fraction of all strains, including $\mathrm{O} 8$ and $\mathrm{O}$. Accordingly, $\operatorname{arc} \mathrm{C}_{\mathbf{x}}$ may represent the core of the antigen molecule. The finding that line $A_{x}$ appeared only with the saline and LPS extracts of strains 08 and 09 , also indicates the unusual structure of these antigens. 
The sensitivity to alkali treatment of certain antigens may be associated with the O-acetyl group content of their side chains.

The present experiments are in agreement with the finding of van Eeden (1967) that trichloracetic acid extracts of $P$. aeruginosa strains exhibited different immunoelectrophoretic patterns. Antigens of van Eeden's four strains running towards the anode correspond to our IE-group I; antigens precipitating on the cathode side are comparable with our group-IV antigens, while those appearing on both sides of the antigen well may belong to our groups II and III.

\section{SUMMARY}

Heated saline extracts of 89 strains, and (1) supernates of phenol-water extracts $\left(\mathrm{L}_{1}\right.$ fractions), (2) purified lipopolysaccharide, (3) trichloracetic-acid (TCA) extracts, and (4) sodium-hydroxide extracts of 23 strains representing all Pseudomonas aeruginosa $\mathrm{O}$ antigens were subjected to electrophoresis. Precipitation lines obtained with homologous and heterologous antisera were evaluated by electrodensitometric measurement. The characteristics of the immunoelectrophoretic groups established were as follows. Group I: two lines running at different rates towards the anode; three subgroups on the basis of the behaviour of alkali-treated antigens. Group $I I$ : triple line at the starting well, alkali sensitive. Group III: triple line at the starting well, alkali resistant; two subgroups according to reactivity or non-reactivity of $L_{1}$ fractions. Group $I V$ : triple line on the cathode side, alkali resistant, $\mathrm{L}_{1}$ fraction non-reactive. Group $V$ : single line on the anode side, alkali sensitive, $L_{1}$ fraction and TCA extract non-reactive. $O$ antigens identified by agglutination corresponded closely with the immunoelectrophoretic pattern: strains with identical $O$ antigens or sharing major somatic components fell, with one exception, into the same immunoelectrophoretic group.

The authors are grateful to Mrs Emese Tóth for skilled technical assistance.

\section{REFERENCES}

ÁdÁm, M. M., Kontrohr, T. AND HoRvÁTH, E. 1971. Serological studies on Pseudomonas aeruginosa $\mathrm{O}$ group lipopolysaccharides. Acta microbiol. hung., 18, 307.

EEDEN, D. VAN. 1967. The antigens of Pseudomonas aeruginosa studied by the Ouchterlony technique and immuno-electrophoresis. J. gen. Microbiol., 48, 95.

HABS, I. 1957. Untersuchungen über die O-Antigene von Pseudomonas aeruginosa. Z. Hyg. InfektKrankh., 144, 218.

LÁNYI, B. 1966-67. Serological properties of Pseudomonas aeruginosa. I. Group-specific somatic antigens. Acta microbiol. hung., 13, 295.

LÁNYI, B. 1970. Serological properties of Pseudomonas aeruginosa. II. Type-specific thermolabile (flagellar) antigens. Acta microbiol. hung., 17, 35.

LÁNYI, B. AND ÁDÁM, M. M. 1973. Double gel diffusion studies on Pseudomonas aeruginosa antigens. Acta microbiol. hung., $20,337$.

SANDVIK, O. 1960. Serological comparison between strains of Pseudomonas aeruginosa from human and animal sources. Acta path. microbiol. scand., 48, 56.

URIEL, J. 1971. In Methods in immunology and immunochemistry, vol. 3, edited by C. A. Williams and M. W. Chase, New York and London, p. 297. 